\title{
Percutaneous endoscopic gastrostomy (PEG): cuil bono?
}

\section{Seamus O’Mahony}

Correspondence to

Dr Seamus O'Mahony,

Gastroenterology Unit, Cork

University Hospital, Wilton, Cork, Ireland;

Seamus.omahony@hse.ie

Received 27 August 2014 Revised 23 September 2014 Accepted 28 September 2014 Published Online First 16 October 2014

\section{CrossMark}

To cite: O'Mahony S. Frontline Gastroenterology 2015:6:298-300

\section{INTRODUCTION}

Percutaneous endoscopic gastrostomy (PEG) insertion became a routine and commonly performed procedure in the early 1990s. PEG feeding was enthusiastically adopted as a treatment for a wide variety of swallowing and nutritional problems. Compared with surgical gastrostomy, it was relatively non-invasive and low-risk, and endoscopists, in the early years of PEG, functioned primarily as technicians, acting on the instruction of physicians from other disciplines. Gradually, however, gastroenterologists began to be concerned about the appropriateness of PEG insertion in many patients referred for the procedure. The 2004 National Confidential Enquiry into Patient Outcome and Death (NCEPOD) report, Scoping our Practice, ${ }^{1}$ drew attention to the strikingly high mortality (6\% at 30 days) in patients following PEG insertion. This report also concluded that nearly a fifth of PEG insertions were 'futile'. In the decade since the NCEPOD report, endoscopists have become more involved in the decision-making process in PEG insertion, and many British acute general hospitals now have multidisciplinary nutrition teams, which enables better decision-making in this complex and emotionally-charged area. Detailed guidelines on PEG insertion have been produced by the British Society of Gastroenterology (BSG), ${ }^{2}$ and a thoughtful document on ethical and practical problems surrounding nutritional care has been published by a working party commissioned by the Royal College of Physicians and the BSG. ${ }^{3}$

Despite these welcome developments, decisions relating to PEG insertion continue to be challenging. Feeding has powerful symbolic, cultural and religious aspects, far beyond the provision of nutrition. Gastroenterologists continue to find themselves in difficult situations, under pressure from families, colleagues and other healthcare workers. For most endoscopists, PEG insertion is the commonest source of ethical difficulty in their clinical practice.

\section{PEG and dementia}

There is now a broad consensus that PEG feeding does not benefit patients with advanced dementia. ${ }^{4} 5$ Over the last 10 years, better education and widespread propagation of clinical guidelines have led, at least in the UK, to a decline in PEG feeding of patients with dementia. This is not the case in the USA, where, despite the lack of benefit, the practice is still widespread. This may be partly explained by the system of remuneration for healthcare: US insurance companies pay hospitals and care homes substantially more for care of PEG-fed patients compared with 'hand-fed' patients. Up to a third of patients in long-term care in the USA are PEG-fed. ${ }^{6}$ Religious and cultural factors may also contribute to this phenomenon.

\section{PEG and 'unsafe swallowing'}

Illustrative case history

The patient is an 83 -year-old man admitted acutely with a chest infection. He has Parkinson's disease, mild cognitive impairment and is quite frail. Prior to admission, his wife looked after him at home. The ward nurses became concerned that he was coughing and spluttering when eating or drinking, and requested an assessment of his swallowing by the speech and language therapist. After an initial bedside assessment, the therapist concluded that the patient's swallow was 'unsafe', and the nursing staff placed a 'Nil By Mouth' sign over the bed. A junior member of the medical team was asked to insert a naso-gastric tube. The patient was confused and pulled out several naso-gastric tubes. The speech and language therapist, the dietitian, the nursing staff and the patient's consultant all agreed that he should now 
have a PEG inserted, and the family was told that this would be the best solution. The gastroenterologist is now faced with a request which, although of dubious appropriateness, will be difficult to refuse.

This so-called 'aspiration' (believed to be caused by 'unsafe swallowing') is now the most difficult and controversial indication for PEG. Aspiration is commonly believed to be caused by laryngopharyngeal aspiration of food and secretions. Videoflouroscopic studies (usually performed by speech and language therapists) are thought to predict the risk of aspiration pneumonia, although there is little evidence that this is the case. Hallenbeck has eloquently summarised the problem: ${ }^{7}$ 'It is worth noting that videoflouroscopy was never developed as a predictive test for aspiration pneumonia; it was developed for the purpose of assisting speech therapists in training patients in new ways of swallowing. Apparently, it works well for this purpose. Clinicians who perform videoflouroscopy found patients with evidence of food "going down the wrong way" and felt they had to do something.'

PEG, surprisingly (and, for many, counter-intuitively) offers no significant protection against aspiration pneumonia: indeed, aspiration pneumonia is the commonest cause of death in PEG-fed patients. This fact-that PEG is a cause of, not a solution to, aspiration pneumonia-causes cognitive dissonance in enthusiasts for PEG as a means of preventing aspiration pneumonia. How could this be? There are a number of possible explanations: (1) PEG feeding does not prevent aspiration of colonised oral secretions; (2) Scintigraphic studies have shown evidence of aspiration of gastric contents in PEG-fed patients; ${ }^{8}$ (3) 'Aspiration' pneumonia in frail, elderly patients may be 'a sign of often unrecognized global physiological decline,, 7 rather than the simplistic 'food going down the wrong way'. Contributing factors include compromised immunity, a suppressed cough reflex and poor respiratory muscle function. The belief, therefore, that bypassing the oropharynx will abolish aspiration pneumonia is largely incorrect. Increasingly, however, hospital inpatients are labelled as having 'unsafe swallow' and declared 'nil by mouth'. This inevitably fuels the demand for PEG insertion. The report of the Royal College of Physicians/BSG working party concluded: 'Coughing and spluttering are not necessarily an indication for "nil by mouth"... "nil by mouth" should be the last resort, not the initial default option'. ${ }^{3}$

It is often assumed that PEG-fed patients should not eat, that it is either PEG or food, but one does not exclude the other: most PEG-fed patients can eat as and when they choose to.

\section{Cui bono?}

Most patients benefit from PEG, but a substantial minority do not, and may even be harmed. In many such cases, persons and agencies other than the patient himself may benefit: (1) Families, who are reassured that the patient is not being 'starved to death'. (2) Hospitals and nursing homes, for whom PEG-feeding is less time-consuming and labour intensive than handfeeding. There is a growing problem of care homes insisting on PEG insertion before accepting hospital patients requiring long-term care: PEG insertion may therefore save the hospital money by facilitating early discharge. (3) Speech and language therapists for whom PEG, which by 'by-passing' the oropharynx, appears to be a neat and simple solution to 'unsafe swallowing'. (4) Dietitians, for whom PEG enables daily caloric targets to be achieved and easily measured. (5) The patient's physician who by requesting PEG insertion satisfies the demands of the parties listed above. (6) The gastroenterologist who realises that proceeding to PEG insertion, although not in the patient's best interest, will assuage parties (1)-(5), a much easier option than engaging in prolonged and difficult discussions around the appropriateness of the procedure. If a family has been advised by a confederacy of nurses, dietitian, speech and language therapist and primary physician that PEG insertion is required, it becomes difficult, if not impossible, for the gastroenterologist to advise against it, particularly when the patient's swallow has been designated 'unsafe'. Difficult decisions, as in this case, are better addressed by a multidisciplinary nutrition team, rather than by the individual endoscopist, and might also lead to fewer patients being labelled as having an 'unsafe swallow'.

The hypothetical (but all too common) patient described above might, with careful hand-feeding, weather his acute episode without the need for tube feeding, and return to home and his baseline state. His 'coughing and spluttering' are likely to improve as his chest infection resolves.

\section{PEG: good for you, but not for me}

Relatives overestimate the benefits of PEG; some believe that the procedure will halt, or even reverse, the underlying disease process. $^{9}$ Compared with gastroenterologists, other physicians have a more optimistic view of PEG feeding in patients with advanced dementia. ${ }^{10}$ Paradoxically, there is evidence that many relatives requesting a PEG would decline a PEG for themselves; ${ }^{11}$ there is some evidence that this applies also to healthcare staff, including speech and language therapists. ${ }^{12} \mathrm{My}$ (anecdotal) experience is that virtually all gastroenterologists and endoscopy nurses would decline a PEG.

\section{The gastroenterologist: physician or technician?}

Writing in 1985, the late Sir Christopher Booth expressed a concern about the direction gastroenterology had taken as a speciality: ${ }^{13}$ 'there is a real danger that some gastroenterologists are allowing themselves to become technicians rather than professional colleagues to be consulted when their help is needed. If another doctor asks for a technique such as endoscopy or liver biopsy to be carried out and the 
gastroenterologist simply responds by carrying out the technique, he is behaving not as a consultant but as a technician.' PEG was a new technique when Booth wrote this, and has become the prime example of what he had warned against.

\section{CONCLUSIONS}

In our acute general hospitals, we observe the paradoxical combination of an obsession with 'nutrition', yet a neglect of food. The simple, quotidian, social, pleasurable activity of eating has evolved into a medical intervention, and a battleground occupied by competing groups.

PEG insertion could be described as a technical panacea for existential problems, problems which, in some cases, are ultimately insoluble. It provides a superficially attractive but overly simplistic answer to these problems, an answer that satisfies families, doctors, nurses, speech and language therapists, dietitians, nurses and long-term care homes. Many (possibly most) patients referred for PEG insertion are unable to express their own wishes. PEG may satisfy the complex professional and personal needs of these various groups, but the patient is often the loser.

Correction notice A sentence under 'Cui bono?' section has been corrected since published Online First.

Contributors This article was conceived and written entirely by Seamus O'Mahony.

Funding None.

Competing interests None.

Provenance and peer review Not commissioned; externally peer reviewed.

\section{REFERENCES}

1 NCEPOD. National confidential enquiry into patient outcome and death: scoping our practice. London: NCEPOD, 2004. http://www.ncepod.org.uk
2 Westaby D, Young A, O'Toole P, et al. The provision of a percutaneously placed enteral tube feeding service. Gut 2010;59:1592-605.

3 Royal College of Physicians. Oral feeding difficulties and dilemmas: a guide to practical care particularly towards the end of life. London: Royal College of Physicians, 2010.

4 Finucane TE, Christmas C, Travis K. Tube feeding in patients with advanced dementia: a review of the evidence. JAMA 1999;282:1365-70.

5 Hoffer LJ. Tube feeding in advanced dementia: the metabolic perspective. BMJ 2006;333:1214-5.

6 Mitchell SL, Teno JM, Roy J, et al. Clinical and organizational factors associated with feeding tube use among nursing home residents with advanced cognitive impairment. JAMA 2003;290:73-80.

7 Hallenbeck JL. Hydration, nutrition, and antibiotics in end-of-life care: tube feed or not tube feed? In: Palliative care perspectives. New York: Oxford University Press, 2003:117-26.

8 Balan KK, Vinjamuri S, Maltby P, et al. Gastroesophageal reflux in patients fed by percutaneous endoscopic gastrostomy (PEG): detection by a simple scintigraphic method. Am J Gastroenterol 1998;93:946-9.

9 Ladas SD, Triantafyllou K, Liappas I, et al. Percutaneous endoscopic gastrostomy: adequacy and quality of information given to decision makers. Dig Dis Sci 2002;20:289-92.

10 Golan I, Ligumsky M, Brezis M. Percutaneous endoscopic gastrostomy in hospitalized incompetent geriatric patients: poorly informed, constrained and paradoxical decisions. Isr Med Assoc J 2007;9:839-42.

11 Mitchell SL, Berkowitz RE, Lawson FM, et al. A cross-national survey of tube-feeding decisions in cognitively-impaired older persons. J Am Geriatr Soc 2000;48:391-7.

12 Sharp HM, Shega JW. Feeding tube placement in patients with advanced dementia: the beliefs and practice patterns of speech-language pathologists. Am J Speech Lang Pathol 2009;18:222-30.

13 Booth CC. What has technology done to gastroenterology? Gut 1985;26:1088-94. 